\title{
Study on Time-Dependent Behavior of Granite and the Creep Model Based on Fractional Derivative Approach Considering Temperature
}

\author{
Zhilei He, ${ }^{1,2}$ Zhende Zhu, $^{1,2}$ Nan Wu, ${ }^{1,2}$ Zhen Wang, ${ }^{1,2}$ and Shi Cheng ${ }^{1,2}$ \\ ${ }^{1}$ Geotechnical Engineering Research Institute of Hohai University, Nanjing, Jiangsu 210098, China \\ ${ }^{2}$ Key Laboratory of Ministry of Education for Geomechanics and Embankment Engineering, Hohai University, Nanjing, \\ Jiangsu 210098, China
}

Correspondence should be addressed to Zhilei He; zlhenj@163.com

Received 19 October 2015; Accepted 17 January 2016

Academic Editor: Riccardo Caponetto

Copyright (C) 2016 Zhilei He et al. This is an open access article distributed under the Creative Commons Attribution License, which permits unrestricted use, distribution, and reproduction in any medium, provided the original work is properly cited.

\begin{abstract}
Based on mineral components and the creep experimental studies of Three Gorges granite and Beishan granite from different regions of China at various temperatures, the strength and creep property of two types of granites are compared and analyzed. Considering the damage evolution process, a new creep constitutive model is proposed to describe the creep property of granite at different temperatures based on fractional derivative. The parameters of the new creep model are determined on the basis of the experimental results of the two granites. In addition, a sensitivity study is carried out, showing effects of stress level, fractional derivative order, and the exponent $m$. The results indicate that the proposed creep model can describe the three creep stages of granite at different temperatures and contribute to further research on the creep property of granite.
\end{abstract}

\section{Introduction}

Since the 1950s, granite has been considered as a potential host rock because of high level radioactive waste disposal because of its high strength, low permeability, and low time-dependent behaviors [1]. Long-lived radionuclide must be emplaced and isolated over thousands of years. Heat generated from the waste in the repository will result in temperature increasing of surrounding rock. Therefore, the research of long-term evolution law and creep mechanism of granite on the condition of high temperature is a key issue for long-term safety prediction of surrounding rock of high level radioactive waste disposal.

Extensive studies have been carried out on the creep property of rock at different temperature. When a rock holds a constant loading, its long-term strain is typically composed of three phases: primary (transient) phase, secondary (steadystate) phase, and tertiary (accelerated) phase. During primary and secondary phases, nucleation and growth of microcracks occur uniformly throughout the rock and the cracks have little tendency to link but instead interact to eliminate regions of high local stress. During the tertiary phase, the crack density reaches a critical level and crack grows further in a weakened region and ultimately develops into a macroscopic fault [2]. Significant thermal influences on creep behavior could be observed in experimental investigations. Generally speaking, the creep strain is proportional to the logarithm of the time under load at temperatures below about $0.2 T_{\mathrm{m}}\left(T_{\mathrm{m}}\right.$ is the absolute temperature of melting). However, at higher temperatures, the creep rate falls off less rapidly with time, and the creep strain is proportional to a fractional power of the time, with the exponent increasing as the temperature increases and reaching a value of $\sim 1 / 3$ at temperatures of about $0.5 T_{\mathrm{m}}$ [3]. The effects of increasing temperatures from 24 to $200^{\circ} \mathrm{C}$ are to weaken the rock considerably and to reduce the time to failure by about two orders of magnitude [4]. However, Indian granites were not showing any shortterm axial creep up to an axial load of $20 \mathrm{t}$ (75.7 MPa) at $160^{\circ} \mathrm{C}$ under unconfined condition, after suffering from heating and cooling process [5]. That is to say, although high 
temperature leads to development of new microcracks or extension/widening of preexisting microcracks within rock, it is not always causing the large displacement and deformation in the creep process. Therefore, it is important to make the mechanism of thermodynamics and creep behavior of rock at high temperature clear.

Based on creep experiments, the creep constitutive models are usually proposed to study the time-dependent behavior of rock. Linear model is often employed to describe viscoelastic properties of rock in earlier research such as Maxwell model, Kelvin model, Kelvin-Voigt model, and Burgers model. These models have the advantage of flexible description of different creep deformation in the transient and steady-state phases of creep, not the tertiary phase. In order to describe thermomechanical behavior of rock, rock creep models with thermomechanical coupling effects were proposed based on the traditional linear creep models [68 ]. These constitutive models can describe the creep behavior very well, but these models usually have more parameters. It will take much time to determine these parameters. However, in recent years, fractional calculus (FC) has attracted an increased attention of scientific society. The theory of FC is a well-adapted tool for modeling of many physical phenomena, allowing the description to take into account some peculiarities that classical integer-order models simply neglect. Fractional derivatives are often used to describe viscoelastic property of materials [9-13]. Some studies have used the fractional derivatives to describe the rheological properties of rock [14, 15], and the results indicate the model with FC operators could give a precise description of the three stages of creep especially the tertiary stage by fitting to the experimental results of time-dependent deformation.

In this paper, creep tests of granites (Three Gorges granite and Beishan granite) from different regions of China at different temperatures were gained by data mining method. The characteristics of strength and creep property of granite were compared and analyzed. On the basis of the creep property, a new creep model was proposed by incorporating thermal damage evolution process based on the theory of fractional calculus. The proposed model was verified by the fitting results of the two types of granites creep tests at different temperatures. Parameters of the proposed model were also determined and analyzed.

\section{Experiment Investigation}

Creep tests of two types of granite (Three Gorges granite and Beishan granite) from different regions of China considering temperature were obtained by data mining. The properties of them are showed as below.

2.1. Three Gorges Granite. Three Gorges granite was taken from the Three Gorges underground powerhouse area. Specimens were prepared with a required dimension of $50 \mathrm{~mm}$ in diameter and $100 \mathrm{~mm}$ in height. Through X-ray diffraction analysis, the mineralogical composition and content of Three Gorges granite are approximately 20 percent biotite, 25 percent quartz, 45 percent feldspar, 5 percent tremolite, and

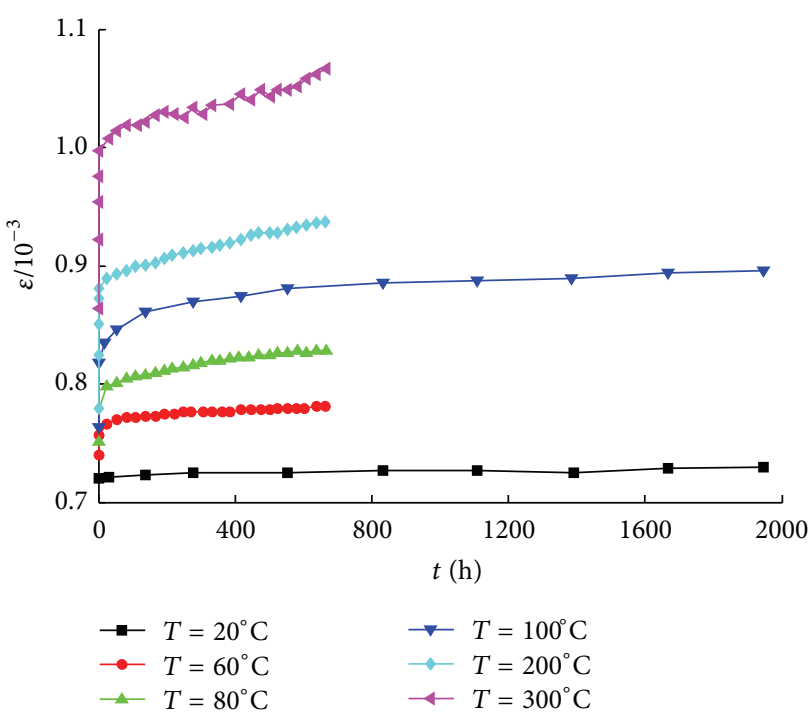

FIgURE 1: Creep test curves of Three Gorges granite under different temperatures.

5 percent others. Compositions are cemented well, extraordinarily dense, and grain growth uniform. It is difficult to break the link between them for each part uniformly when suffering from pressure. The mineral composition and microstructure of Three Gorges granite decide its high strength. However, the strength will decrease owing to weathering [16].

The experiment was carried out at Japan's Institute for Resources and Environment using MTS higher temperature and higher pressure testing machine. In the process, a triaxial chamber was firstly heated to the required temperature and kept constant for 4 hours in order to form a uniform temperature field and then started to apply the loading. A series of uniaxial compression creep tests were performed on the condition of keeping the axial stress of $120 \mathrm{MPa}$. The temperature was, respectively, controlled at $20^{\circ} \mathrm{C}, 60^{\circ} \mathrm{C}$, $80^{\circ} \mathrm{C}, 100^{\circ} \mathrm{C}, 200^{\circ} \mathrm{C}$, and $300^{\circ} \mathrm{C}$. The results are showed in Figure 1 . The creep test was kept approximately $8300 \mathrm{~h}$ at the temperature of $20^{\circ} \mathrm{C}, 4200 \mathrm{~h}$ at the temperature of $100^{\circ} \mathrm{C}$ and $700 \mathrm{~h}$ at other temperatures $[17,18]$. As shown in Figure 1, the creep process of Three Gorges granite consists of primary phase and steady-state phase. Instantaneous strain gradually increases with temperature and elastic modulus decreases with temperature. Creep rate increases fast at first and then gradually decreases with time and finally tends to 0 at the same temperature. However, at higher temperatures, the creep strain and creep rate increase with temperature. That is, high temperature causes the damage of rock and speeds up the creep process.

2.2. Beishan Granite. Beishan granite was taken from Beishan site which is considered as a potential disposal site for China's repository [19]. Beishan granite is classified as porphyritic monzonitic granite. It is gray porphyritic texture and massive structure. The mineral composition and content of granite are about $20-25$ percent quartz, 35-40 percent plagioclase, 30-35 percent alkali-feldspar, 5 percent biotite, and others. 


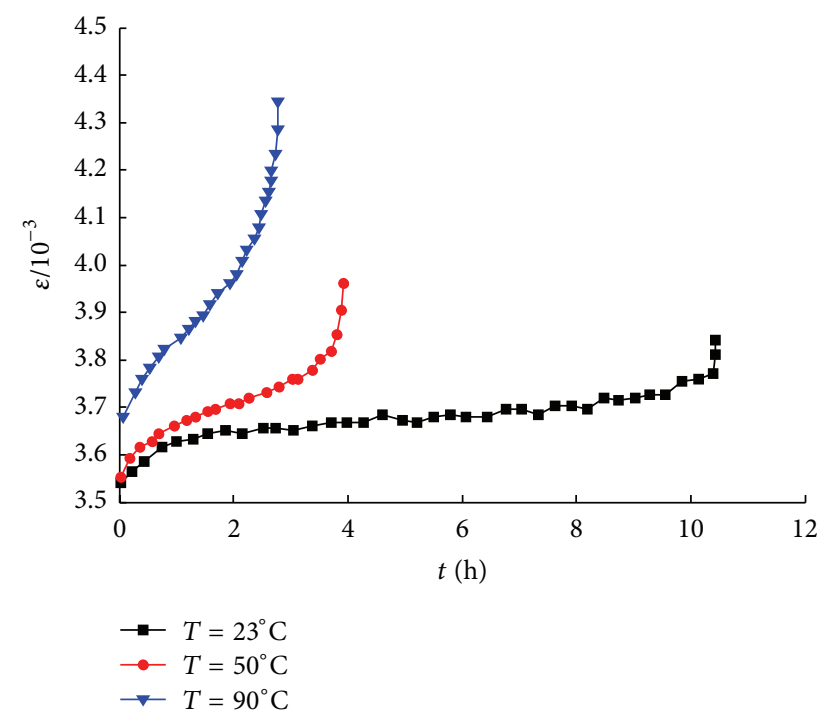

FIGURE 2: Creep strain curves of Beishan granite at different temperatures.

The grain density of porphyritic monzonitic granite is $2.71 \mathrm{~g} / \mathrm{cm}^{3}$ and the natural density is $2.64 \mathrm{~g} / \mathrm{cm}^{3}$. The porosity and water content of specimens are low. The average compressive wave velocity is about $5423 \mathrm{~m} / \mathrm{s}$ (range: $5197-5549 \mathrm{~m} / \mathrm{s}$ ). In addition, the uniaxial compression strength of specimens is $129-140 \mathrm{MPa}[20,21]$.

The uniaxial compression creep tests of Beishan granite were carried out at the University of Hong Kong. The creep tests were conducted using a MTS 815 rock mechanics test system. The specimens for the test were prepared about $50 \mathrm{~mm}$ in diameter and $100 \mathrm{~mm}$ in height, following the standard for test method of engineering rock mass. The results of uniaxial compression creep test at different temperatures are showed in Figure $2\left(T=23^{\circ} \mathrm{C}, \sigma=118 \mathrm{MPa}\right.$; $\left.T=50^{\circ} \mathrm{C}, \sigma=125 \mathrm{MPa} ; T=90^{\circ} \mathrm{C}, \sigma=121 \mathrm{MPa}\right)$ [8]. As shown in Figure 2, the creep process of Beishan granite can be divided into three phases: the transient creep phase, the steady creep phase, and the accelerated creep phase. Instantaneous strain increases with temperature. The average elastic modulus slightly decreases with temperature. The strain rate decreases monotonically during the transient creep stage, keeps constant in steady-state phase, then increases abruptly in the accelerated creep phase, and ultimately leads to sample failure. The creep strain change rate became more pronounced with the increase of temperature. The steady-state creep strain rate at $90^{\circ} \mathrm{C}$ is about one order of magnitude higher than the value at $23^{\circ} \mathrm{C}$ and the occurrence of the accelerated creep phase and rock failure is also much earlier at higher temperature.

The creep tests of the two types of granite from different regions were performed at different temperature. The creep deformation is increasing with temperature. In comparison to the creep results of Three Gorges granite at $20^{\circ} \mathrm{C}, 120 \mathrm{MPa}$ and Beishan granite at $23^{\circ} \mathrm{C}, 118 \mathrm{MPa}$, their creep properties are different. Creep curve of Three Gorges granite is only the transient creep phase and then the strain rate decreases and tends to 0 . However, creep curve of Beishan granite includes three creep phases and then the creep rate decreases gradually to a certain value. But the strain rate increases abruptly in accelerated phase. The failure time of creep is about $1.1 \mathrm{~h}$. In terms of creep strain level, instantaneous strain of Three Gorges granite is about $0.71 * 10^{-3}$, the creep strain increases with time, and finally the creep strain reaches to $0.73 * 10^{-3}$, while instantaneous strain of Beishan granite is about $3.56 * 10^{-3}$. Then the creep strain increases gradually and reaches to $3.65 * 10^{-3}$ at steady-state phase. But the strain abruptly increases and reaches to $3.7 * 10^{-3}$ when creep failure occurs. By contrasting the creep strain level, creep strain of Three Gorges granite is obviously smaller. In comparison to the results of Three Gorges granite at $100^{\circ} \mathrm{C}, 120 \mathrm{MPa}$ and Beishan granite at $90^{\circ} \mathrm{C}, 125 \mathrm{MPa}$, there is a similar law to the previous situation. In a word, high temperature will cause thermal damage and the creep rate of rock will increase with temperature. By the comparison of the two types of granite, the result indicates that the creep property of Three Gorges granite is more stable than that of Beishan granite at high temperature.

Rock creep failure at high temperature is the result of thermal damage and stress damage coupling effect in nature. Thermal fracture for temperature and damage fracture for stress will produce the composite failure process. The cracks which are produced for the coupling effect will extend with time. The structure of rock is broken gradually. On the micro scale, these phenomena of dislocation and diffusion of lattice defect, intergranular coordination deformation and initiation, and propagation and linking of microcrack will take place. On the macro scale, the strength degradation and creep fracture will also be observed correspondingly. From the perspective of phenomenology, the creep rate will be faster with the increasing of temperature. The relationship of the creep rate and stress is not simple linear but nonlinear one and varies with stress and temperature.

In order to describe the nonlinear relationship, on the basis of the above experimental research, a new mechanismbased creep constitutive model is proposed by using the theory of fractional calculus.

\section{The Theory of Fractional Calculus and Abel Dashpot}

Fractional calculus is a field of mathematic study that grows out of the traditional definitions of calculus integral and derivative operators; in much the same way fractional exponent is an outgrowth of exponents with integer value. It is also a mathematical tool which can effectively solve physical and mechanical modeling problems. It has been used successfully to modify many existing models of physical processes. Fractional order models often work well, particularly for dielectrics and viscoelastic materials over extended ranges of time and frequency.

There are several definitions of the fractional calculus. The most famous ones of these definitions that have been popularized in the field of fractional calculus are the Riemann-Liouville definition and Grunwald-Letnikov 


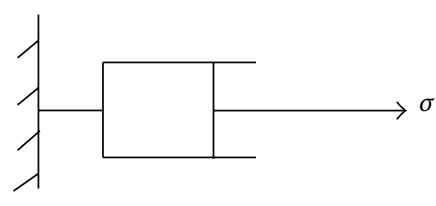

(a) Newton dashpot

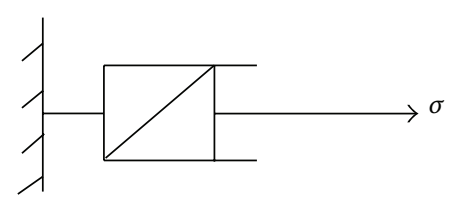

(b) Abel dashpot

Figure 3: Newton dashpot and Abel dashpot.

definition. In this paper, the Riemann-Liouville definition will be introduced to describe the rheology of rock. For arbitrary real or complex number $n, \operatorname{Re}(n)>0, n$-fold integral of function $f(t)$ is defined as follows:

$$
D^{-n} f(t) \frac{d^{-n}[f(t)]}{d t^{-n}}=\frac{1}{\Gamma(n)} \int_{0}^{t}(t-\xi)^{n-1} f(\xi) d \xi
$$
$n>0$,

where $\Gamma(\cdot)$ is the Gamma function.

The same definition can be used for fractional derivative of order $n$ by a formal replacement of $-n$ by $n$ [22]

$$
D^{n} f(t) \frac{d^{n}[f(t)]}{d t^{n}}=\frac{1}{\Gamma(-n)} \int_{0}^{t}(t-\xi)^{-n-1} f(\xi) d \xi
$$

$$
n>0 \text {. }
$$

Let us discuss the reason why the use of fractional derivatives for the mathematical modeling of viscoelastic materials is quite natural.

The well-known relationships between stress and strain for solids are as follows:

$$
\sigma(t)=E \varepsilon(t) .
$$

For Newtonian fluids

$$
\sigma(t)=\eta \frac{d \varepsilon(t)}{d t}
$$

where $E$ and $\eta$ denote the spring constant and the viscosity and $\sigma(t)$ and $\varepsilon(t)$ are stress and strain.

Relationships (3) and (4) are not universal laws; they are only mathematical models for an ideal solid material and for an ideal fluid, neither of which exists in the real world. In fact, real materials combine properties of those two limit cases and lie somewhere between ideal solids and ideal fluids, if materials are sorted with respect to their firmness. Noting that stress is proportional to the zeroth derivative of strain for solids and to the first derivative of strain for fluids, it is natural to suppose, as has been done by Blair [23], that for "intermediate" materials stress may be proportional to the strain derivative of "intermediate" (noninteger) order.

The Hooke elastic element is represented as a spring, while the Newton viscous element is shown as a dashpot. It is common practice in rheology to manipulate with such representations instead of corresponding equations. We call this constitutive relation with fractional derivative the Scott Blair element, or Abel dashpot, as shown in Figure 3:

$$
\sigma(t)=\eta^{n} \frac{d^{n} \varepsilon(t)}{d t^{n}} \quad 0 \leq n \leq 1,
$$

where $\eta^{n}$ is the viscosity coefficient of Abel dashpot (A for short).

When stress is a constant, $\sigma(t)=\sigma$, the Able dashpot can describe a creep process. According to the theory of Riemann-Liouville, (5) can be transformed to (6) by fractional integral [14]

$$
\varepsilon(t)=\frac{\sigma}{\eta^{n}} \frac{t^{n}}{\Gamma(1+n)} \quad 0 \leq n \leq 1,
$$

where $n$ take different values, and the creep curve of Abel dashpot describing is shown in Figure 4.

\section{Creep Constitutive Model Based on Fractional Derivative}

The nature of fractional derivative constitutive model is replacing the Newtonian dashpot in the classical models with the Abel dashpot. A new creep constitutive model is proposed, which is composed of the Hooke body $(\mathrm{H})$, the viscoelastic body (A), and the viscoplastic body (A/St.V), as shown in Figure 5.

The total strain in Figure 7 is given by

$$
\varepsilon=\varepsilon_{e}+\varepsilon_{\mathrm{ve}}+\varepsilon_{\mathrm{vp}},
$$

where $\varepsilon_{e}, \varepsilon_{\mathrm{ve}}$, and $\varepsilon_{\mathrm{vp}}$ are the strains of Hook body, the viscoelastic body, and the viscoplastic body, respectively.

For the Hook body $(\mathrm{H})$, the effect of temperature for rock rheology can be described by linear coefficient of thermal expansion. The constitutive relation considering temperature effect is given by

$$
\begin{aligned}
\sigma & =E(T) \varepsilon_{e}-E(T) \alpha(T) \Delta T \\
\varepsilon_{e} & =\frac{\sigma}{E(T)}+\alpha(T) \Delta T,
\end{aligned}
$$

where $\sigma$ is the applied stress, $\varepsilon_{e}$ is the strain, $\alpha$ is the coefficient of thermal expansion, $\Delta T$ is the difference in temperature, and $E(T)$ is the elastic modulus at the temperature $T$. If the temperature is constant, the strain can be expressed as

$$
\varepsilon_{e}=\frac{\sigma}{E(T)} .
$$

For the viscoelastic body (A), the Abel dashpot is a fractional derivative description of the Newtonian dashpot. The constitutive equation can be written as

$$
\sigma(t)=\eta^{n} \frac{d^{n} \varepsilon(t)}{d t^{n}}
$$




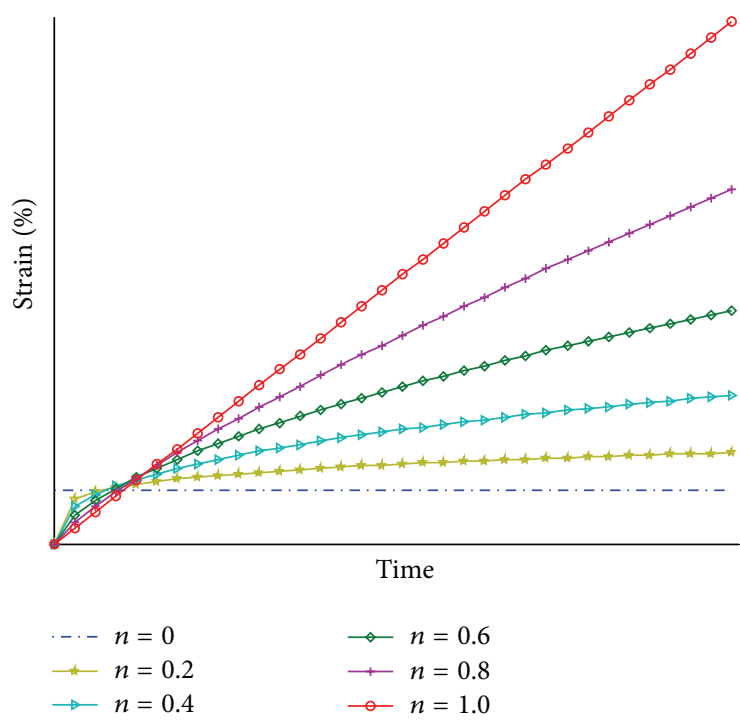

FIgURE 4: Creep curves of Abel dashpot.
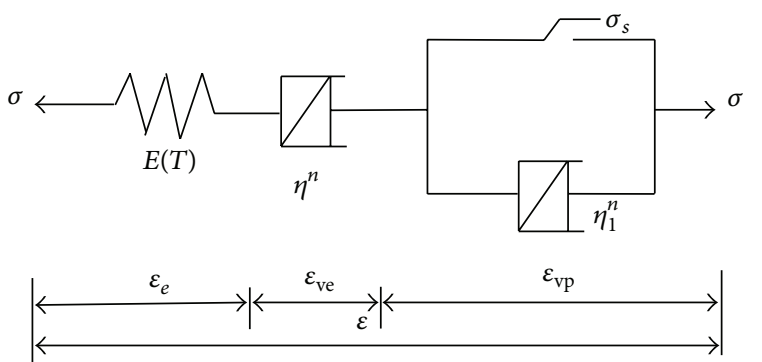

FIGURE 5: Schematic view of the fractional derivative creep model.

Let the stress $\sigma(t)$ be constant; (10) can be rewritten as

$$
\varepsilon_{\mathrm{ve}}=\frac{\sigma}{\eta^{n}} \frac{(t)^{n}}{\Gamma(1+n)} \quad(0<n \leq 1) .
$$

According to above tests, in the creep process, especially in the accelerated phase, the creep rate of granite usually appears to continuously increase up to failure, resulting from damage growth and crack development of thermomechanical coupling at the micro- and mesoscale. Therefore, it is suggested that the viscosity coefficient may no longer be constant and decreases with the damage growth. Considering an effect of damage growth on the creep process, the damage variable is a function with a negative exponent $[8,14]$. The damage evolution during creep process can be estimated by a function with a negative exponent

$$
D=1-e^{-m t} .
$$

In the equation, $D$ is the damage variable varying from 0 to 1 , corresponding to the intact and completely damaged states, respectively. $m$ is a material parameter controlling the damage evolution process with temperature. This simplified damage criterion is adopted in our study to simulate the time-dependent subcritical cracking process considering temperature. Now, Abel dashpot is a variable viscosity one and $\eta_{1}^{n}$ is not a constant but varies with damage variable and temperature

$$
\eta_{1}^{n}(T, D)=\eta_{1}^{n}(T)(1-D)
$$

For the viscoplastic body (A/St.V), the stress $\sigma_{p}$ of the fractional element is given by

$$
\sigma_{p}= \begin{cases}\sigma & \sigma<\sigma_{s} \\ \sigma_{s} & \sigma \geq \sigma_{s},\end{cases}
$$

where $\sigma_{s}$ is the yield limit.

The total stress $\sigma$ of the coupled thermoviscoplastic damage element is given by

$$
\sigma=\sigma_{d}+\sigma_{p}
$$

where $\sigma_{d}$ is the stress on the variable viscosity Abel dashpot.

If $\sigma<\sigma_{s}, \sigma_{d}=0$, then,

$$
\varepsilon_{\mathrm{vp}}=0 .
$$

If $\sigma \geq \sigma_{s}$, by substituting (12), (13), and (14) into (15), then

$$
\sigma_{d}=\sigma-\sigma_{s}=\eta_{1}^{n}(1-D) \frac{d^{n} \varepsilon_{\mathrm{vp}}}{d t^{n}}
$$

Namely,

$$
\frac{d^{n} \varepsilon_{\mathrm{vp}}}{d t^{n}}=\frac{\sigma-\sigma_{s}}{\eta_{1}^{n}} e^{m t}
$$

Laplace transform

$$
E(s)=\frac{\sigma-\sigma_{s}}{\eta_{1}^{n} s^{n}} \frac{1}{s-m} .
$$

Inverse Laplace transform

$$
\varepsilon_{\mathrm{vp}}=\frac{\sigma-\sigma_{s}}{\eta_{1}^{n}} t^{n} \sum_{k=0}^{\infty} \frac{(m t)^{k}}{\Gamma(k+n+1)} \quad 0 \leq n \leq 1 .
$$

Therefore, the constitutive relationship of the viscoplastic body is given by

$$
\begin{aligned}
& \mathcal{E}_{\mathrm{vp}} \\
& \quad= \begin{cases}0 & \sigma<\sigma_{s}, 0 \leq n \leq 1 \\
\frac{\sigma-\sigma_{s}}{\eta_{1}^{n}} t^{n} \sum_{k=0}^{\infty} \frac{(m t)^{k}}{\Gamma(k+n+1)} & \sigma \geq \sigma_{s}, 0 \leq n \leq 1 .\end{cases}
\end{aligned}
$$

The detailed derivation process can also be seen in Zhou's literature [14]. 
TABLE 1: Principal parameters determined by fitting analysis based on creep tests of Three Gorges granite.

\begin{tabular}{|c|c|c|c|c|c|}
\hline Temperature $/{ }^{\circ} \mathrm{C}$ & $E / G P a$ & $\eta^{n} / 10^{3} \mathrm{GPa} \cdot \mathrm{h}$ & $\eta_{1}^{n} / 10^{3} \mathrm{GPa} \cdot \mathrm{h}$ & $m / \mathrm{h}^{-1}$ & $n$ \\
\hline 20 & 167 & 20.2 & - & - & 0.54 \\
\hline 80 & 152 & 7.94 & - & - & 0.45 \\
\hline 300 & 120 & 8.70 & - & - & 0.71 \\
\hline
\end{tabular}

TABLE 2: Principal parameters determined by fitting analysis based on creep tests of Beishan granite.

\begin{tabular}{lcccrr}
\hline Temperature $/{ }^{\circ} \mathrm{C}$ & $E / \mathrm{GPa}$ & $\eta^{n} / 10^{3} \mathrm{GPa} \cdot \mathrm{h}$ & $\eta_{1}^{n} / 10^{6} \mathrm{GPa} \cdot \mathrm{h}$ & & $m / \mathrm{h}^{-1}$ \\
\hline 23 & 332 & 18 & 3.13 & 0.29 \\
50 & 346 & 8.8 & 0.99 & 01 & 2.57 \\
90 & 342 & 7.9 & 0.48 & 0.29 \\
\hline
\end{tabular}

A total creep strain of all the constitutive models can be written as

$$
\begin{aligned}
\varepsilon(t)= & \frac{\sigma}{E(T)}+\alpha(T) \Delta T+\frac{\sigma}{\eta^{n}} \frac{(t)^{n}}{\Gamma(1+n)} \\
\varepsilon(t)= & \frac{\sigma}{E(T)}+\alpha(T) \Delta T+\frac{\sigma}{\eta^{n}} \frac{(t)^{n}}{\Gamma(1+n)} \\
& +\frac{\sigma-\sigma_{s}}{\eta_{1}^{n}} t^{n} \sum_{k=0}^{\infty} \frac{(m t)^{k}}{\Gamma(k+n+1)} \\
& \quad \sigma \geq \sigma_{s}, 0 \leq n \leq 1,
\end{aligned}
$$

If the temperature keeps constant, the creep constitutive model can be rewritten as

$$
\begin{aligned}
\varepsilon(t)= & \frac{\sigma}{E(T)}+\frac{\sigma}{\eta^{n}} \frac{(t)^{n}}{\Gamma(1+n)} \quad \sigma<\sigma_{s}, 0 \leq n \leq 1 \\
\varepsilon(t)= & \frac{\sigma}{E(T)}+\frac{\sigma}{\eta^{n}} \frac{(t)^{n}}{\Gamma(1+n)} \\
& +\frac{\sigma-\sigma_{s}}{\eta_{1}^{n}} t^{n} \sum_{k=0}^{\infty} \frac{(m t)^{k}}{\Gamma(k+n+1)} \\
& \sigma \geq \sigma_{s}, 0 \leq n \leq 1 .
\end{aligned}
$$

\section{Verification and Analysis of Proposed Creep Model}

The efficacy of the proposed creep model to full creep process is dependent on its ability to adequately fit the experimental data [8]. All parameters in the model can be determined from the experimental tests with a nonlinear least-squares fitting method, namely, the Levenberg-Marquardt method. Leastsquares fits of the fractional derivative model given by (23a) and (23b) to the Three Gorges granite and Beishan granite experimental data result in the parameters presented in Tables 1 and 2. The data and the fitting curves to the fractional derivative constitutive model are shown in Figure 6.

According to the fitting results of existing data under different temperatures presented in Tables 1 and 2 and
Figure 6, the proposed model can describe three creep phases of granite at different temperatures very well, especially the accelerated creep phase. Parameters of model are determined easily. Most of the model parameters, including the elastic modulus and viscosity coefficients, are decreased with temperature. The variation laws of elastic modulus and viscosity coefficient with temperature are presented in Figure 7. This indicates that degree of damage of granite at high temperature is accumulated with temperature, which worsens the structure, lowers the strength, and is attributed to the failure of rocks. Meanwhile this also proves that it is important and reasonable considering the damage evolution process in creep deformation process.

\section{Parametric Analysis and Discussion}

It is obvious that the time-dependent strain of granite depends on several parameters, as shown in (23b), among which the stress level and viscosity coefficients $\eta^{n}, \eta_{1}^{n}, m$, and $n$ are the most important ones. In order to have a better understanding of the effects of those parameters on the timedependent deformation of granite, parametric analysis has been carried out. By substituting $\sigma=119 \mathrm{MPa}, \sigma_{s}=104 \mathrm{MPa}$, $E=331 \mathrm{GPa}, \eta^{n}=1.8 \times 10^{4} \mathrm{GPa} \cdot \mathrm{h}, \eta_{1}^{n}=3.13 \times 10^{6} \mathrm{GPa} \cdot \mathrm{h}$, $m=1.01$, and $n=0.29$ into (23b), a series of creep curves are obtained under the cases of different stress levels $\sigma$, derivative orders $n$, and exponents $m$.

6.1. Effect of the Stress Level $\sigma$. By substituting $\sigma_{s}=104 \mathrm{MPa}$, $E=331 \mathrm{GPa}, \eta^{n}=1.8 \times 10^{4} \mathrm{GPa} \cdot \mathrm{h}, \eta_{1}^{n}=3.13 \times 10^{6} \mathrm{GPa} \cdot \mathrm{h}$, $m=1.01$, and $n=0.29$ into (23b) and letting stress level $\sigma$ change from 109 to $119 \mathrm{MPa}$ with an interval of $5 \mathrm{MPa}$, a series of strain-time curves are presented in Figure 8. The result shows that the higher the stress level, the larger the creep strain of granite. That is, stress level has an important effect on the degree of strain, while it has little influence on the creep rate within certain limits.

6.2. Effect of the Fractional Derivative Order $n$. Letting the fractional derivative order $n$ change from 0 to 1 with an interval of 0.2 and other parameters be constant in (23b), a series of curves are shown in Figure 9, indicating that the creep strain and the creep rate are very dependent on 


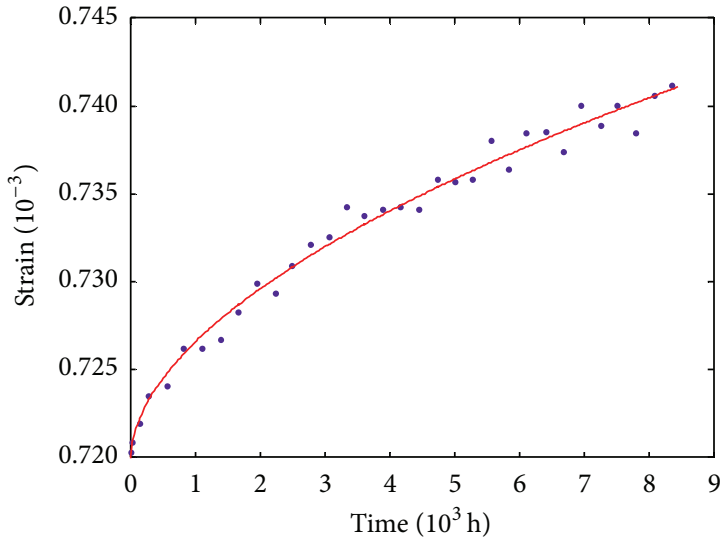

- Experimental data Model prediction

(a) Three Gorges granite on the condition of $T=20^{\circ} \mathrm{C}, \sigma=$ $120 \mathrm{MPa}$

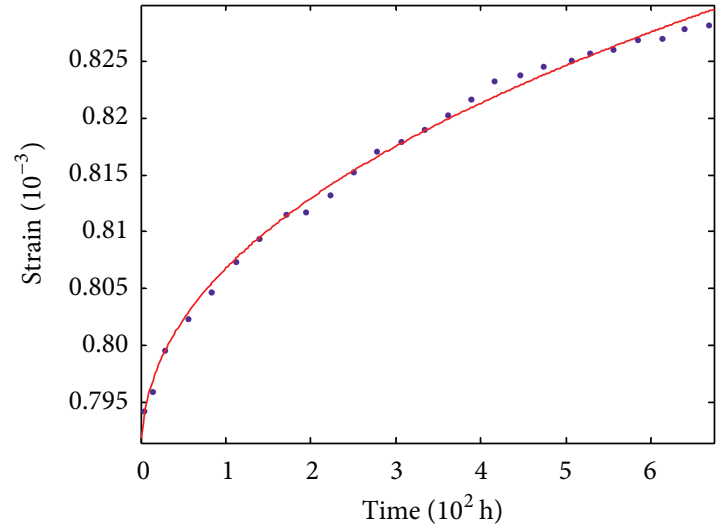

- Experimental data

— Model prediction

(c) Three Gorges granite on the condition of $T=80^{\circ} \mathrm{C}, \sigma=$ $120 \mathrm{MPa}$

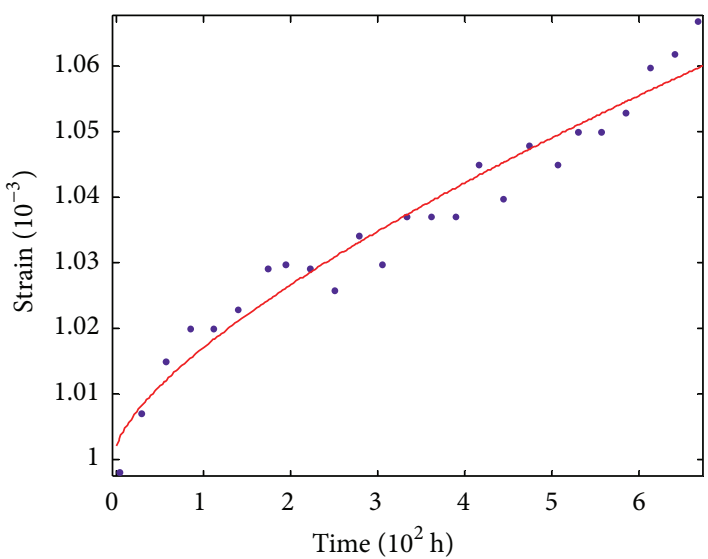

- Experimental data

(e) Three Gorges granite on the condition of $T=300^{\circ} \mathrm{C}, \sigma=$ $120 \mathrm{MPa}$

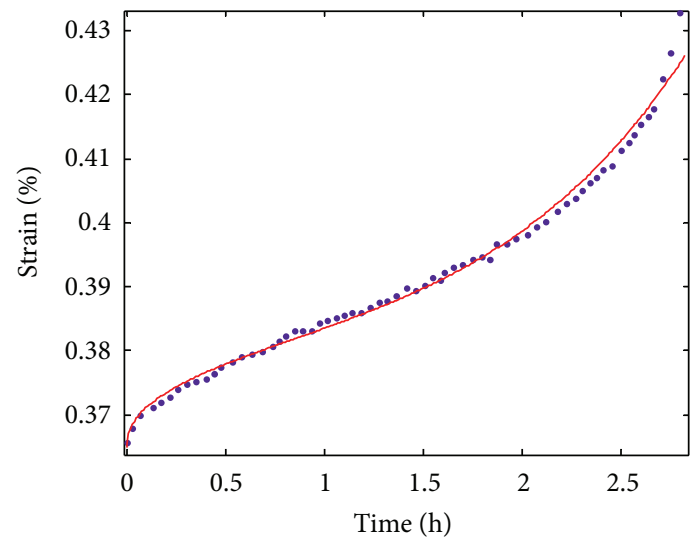

- Experimental data

- Model prediction

(b) Beishan granite on the condition of $T=23^{\circ} \mathrm{C}, \sigma=$ $118 \mathrm{MPa}$

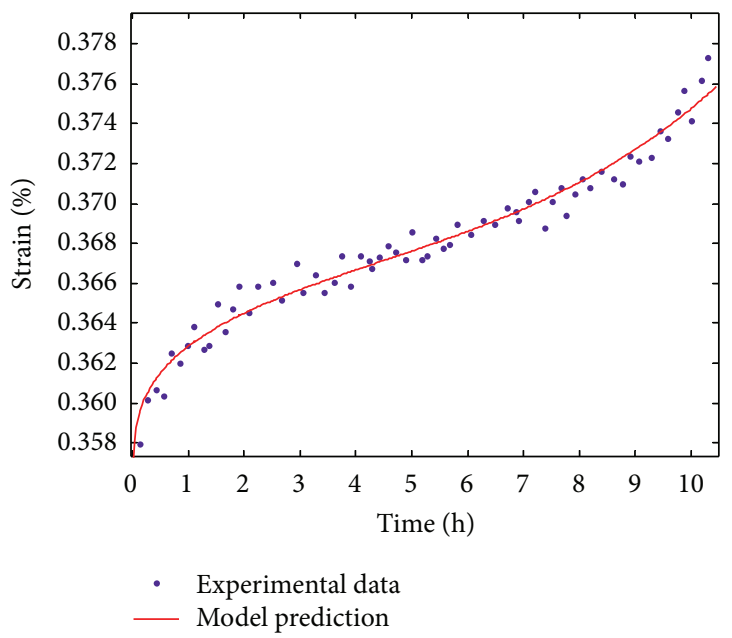

(d) Beishan granite on the condition of $T=50^{\circ} \mathrm{C}, \sigma=125 \mathrm{MPa}$

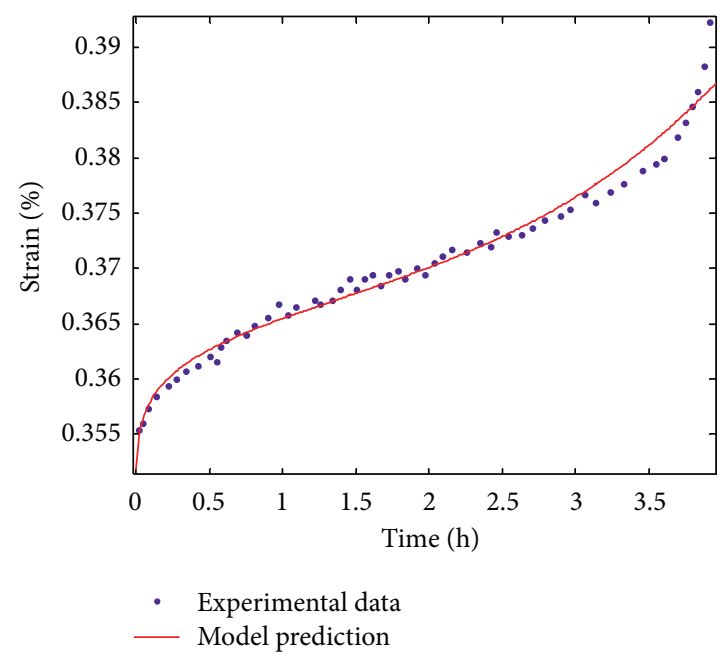
(f) Beishan granite on the condition of $T=90^{\circ} \mathrm{C}, \sigma=121 \mathrm{MPa}$

FIGURE 6: Comparison of experimental data and the fitting curves of the proposed creep model. 


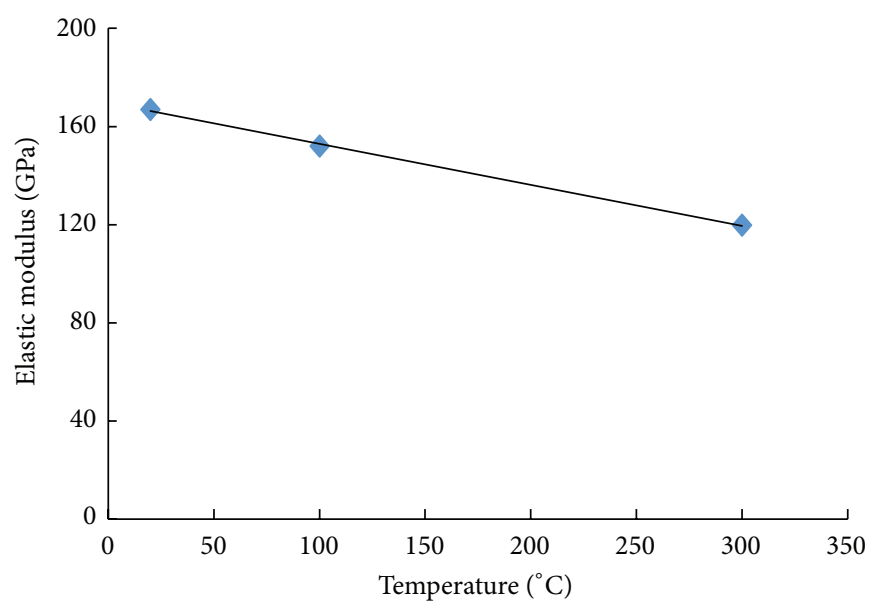

Calculated value - Fitting curve

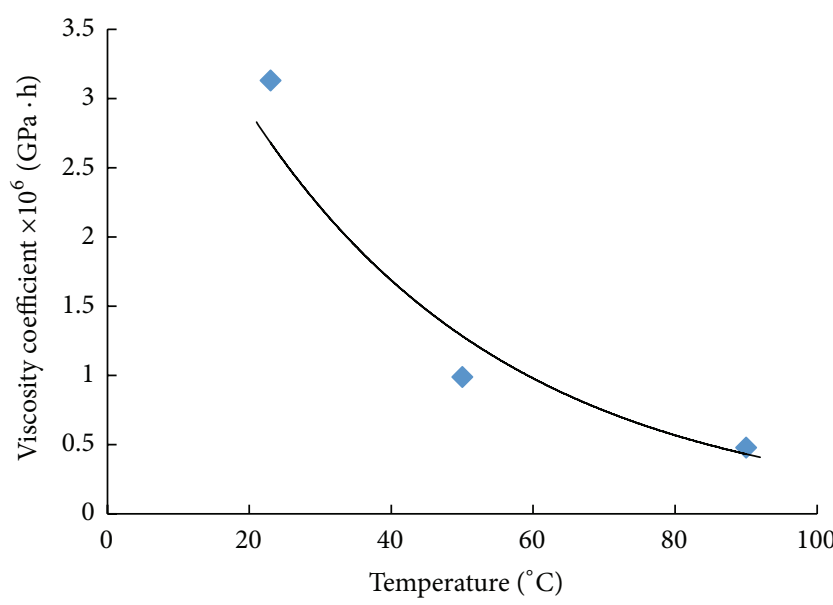

Calculated values

- Fitting curve

FIgURE 7: Calculated value and fitting curves of elastic modulus and viscosity coefficient.

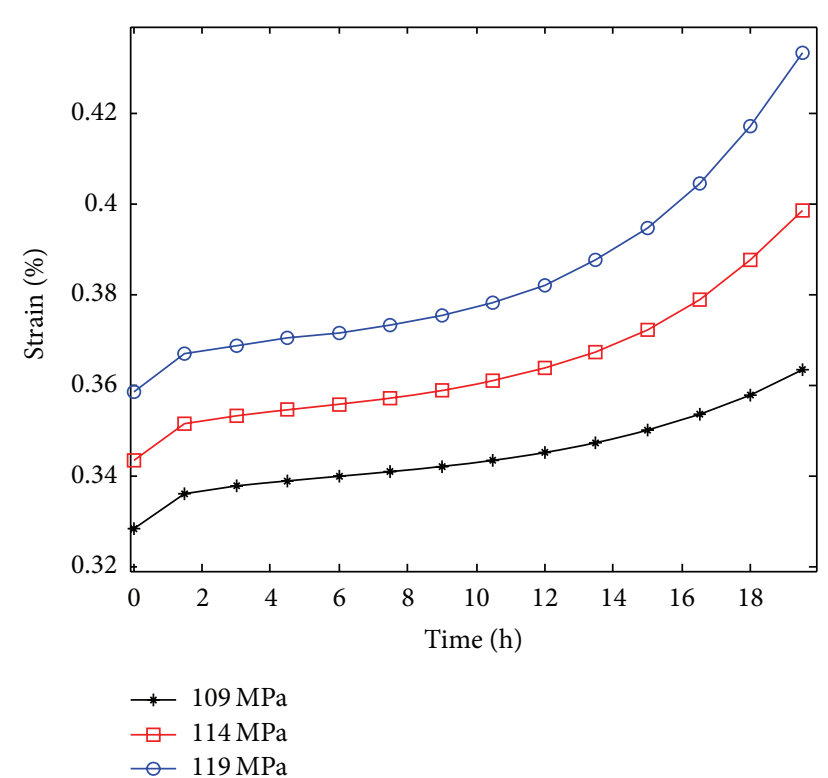

FIGURE 8: Sensitivity of the creep strain to the stress level $\sigma$.

the fractional derivative order. A higher value of derivative order usually leads to a greater creep strain, a higher strain rate, and a shorter period of steady creep.

6.3. Effect of the Exponent $m$. A series of curves are obtained by changing the exponent $m$ and keeping other parameters invariable in (23b), as shown in Figure 10. The results show that the occurrence of accelerated creep stage is much earlier and the creep rate and creep deformation generated in accelerated creep stage also become greater with the increase of $m$.

In this paper, time-dependent behavior of granites from different regions of China is compared and analyzed considering the temperature by the method of data mining.

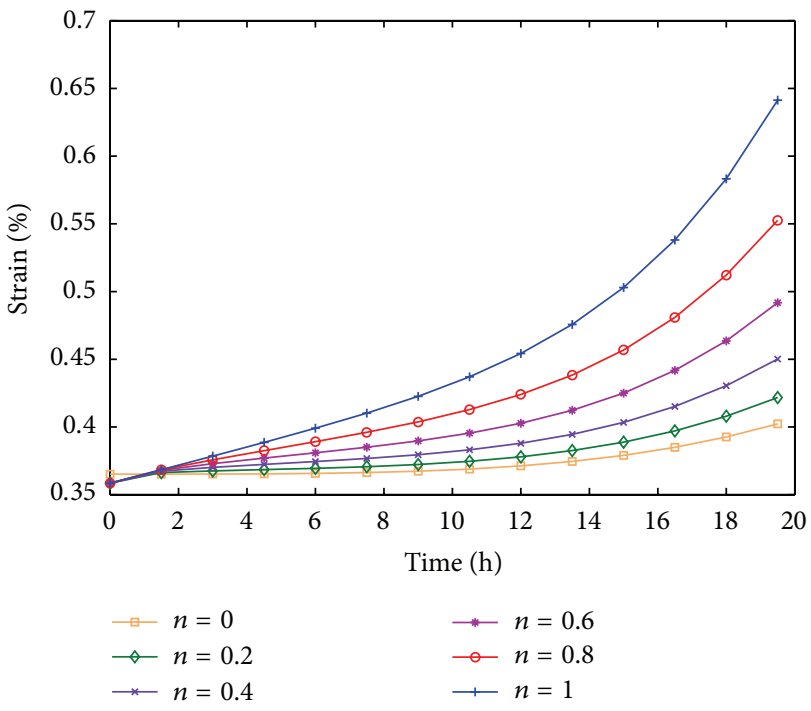

FIGURE 9: Sensitivity of the creep strain to the fractional derivative order $n$.

However, the comparison is of just two aspects: mineral compositions and creep property of granite. This is not comprehensive. In recent years, numerical modeling technology develops quickly; the applications also increase gradually in describing the deformation behavior of rock mass. A very important task next is the relationship analysis of compositions, structure, and failure mechanics of rock mass in the view of macromesoscopic combination by the method of discrete elements and to establish the quantitative relation between the compositions and the property of rock mass. Meanwhile, it should be noted, although a new creep model is presented in this paper, that the fractional derivative model is still a mathematical expression based on the fractional derivative theory. Further research on the physical meaning of the derivative order is important and necessary. 


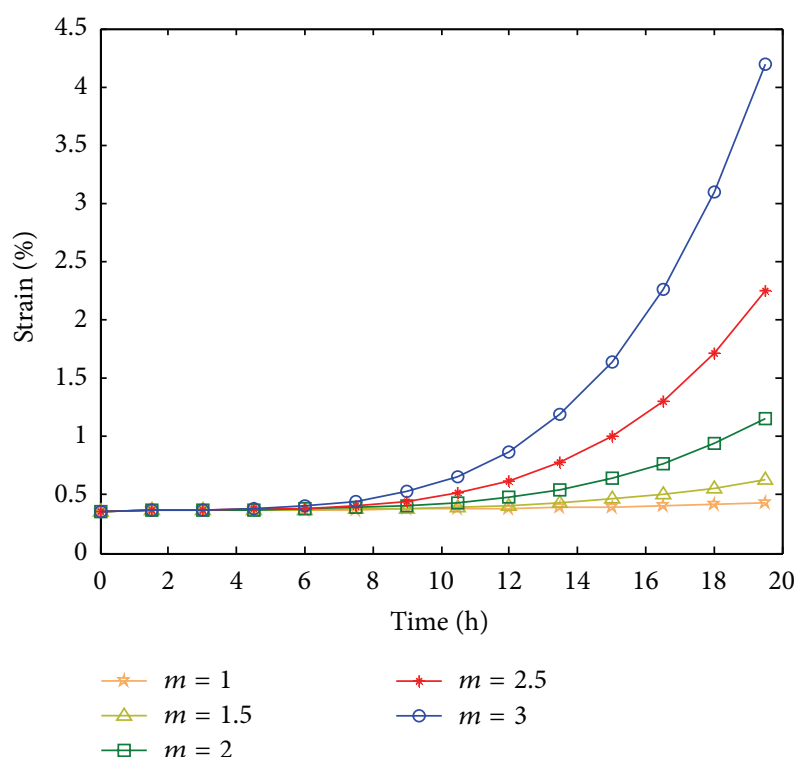

FIGURE 10: Sensitivity of the creep strain to the exponent $m$.

\section{Conclusions}

In this study, two types of granites from different regions of China were compared and analyzed in terms of the mineral compositions and thermal-creep behavior. Based on the experimental data, a new thermal-creep constitutive model was proposed by using the theory of fractional calculus. The parameters are determined by fitting to experimental results of time-dependent deformation of granites. A sensitivity study shows the effects of stress level, fractional derivative order, and viscosity coefficient exponent on the creep process of granite. The main conclusions are drawn as follows:

(1) By the comparison of the creep property of Beishan granite and Three Gorges granite, the results show Three Gorges granite has small deformation on a similar condition of temperature and stress. That is, the creep property of Three Gorges granite is more stable than that of Beishan granite considering temperature.

(2) A new fractional derivative creep model is proposed in the paper incorporating damage evolution process at high temperature. The model is able to reproduce the full creep process of granite at different temperatures. By the fitting analysis, the creep model is proved to be reasonable and simple. The fractional derivative order $n$, exponent $m$, and stress level $\sigma$ are important parameters. Sensitivity analysis shows that the higher the stress level, the larger the creep strain of granite, derivative order $n$, and exponent $m$ governing the creep rate and the shape of creep curves and the higher $n$ and $m$, the shorter the steady stage of creep.

It should be noted that the research is just a preliminary work, and an important task next is the analysis of mineral compositions, structure, and failure mechanics of rock mass in the view of macromesoscopic combination and to establish the quantitative relation between the components and the property of rock mass. What is more, the physical meaning of the fractional derivative should be further researched.

\section{Conflict of Interests}

The authors declare that there is no conflict of interests regarding the publication of this paper.

\section{Acknowledgments}

This research is supported by the National Natural Science Foundation of China $(41272329,51379065)$, the 973 Program (2011CB013504), the Fundamental Research Funds for the Central Universities (2014B33614), and the Natural Science Foundation of Jiangsu Province (Grant no. BK20130846). They are gratefully acknowledged.

\section{References}

[1] P. A. Witherspoon and G. S. Bodvarsson, Eds., Geological Challenges in Radioactive Waste Isolation: Third Worldwide Review, Escholarship University of California, 2001.

[2] Q. X. Lin, Y. M. Liu, L. G. Tham, C. A. Tang, P. K. K. Lee, and J. Wang, "Time-dependent strength degradation of granite of saturated gran," International Journal of Rock Mechanics and Mining Sciences, vol. 46, no. 7, pp. 1103-1114, 2009.

[3] A. K. Misra and S. A. F. Murrell, "An experimental study of the effect of temperature and stress on the creep of rocks," Geophysical Journal International, vol. 9, no. 5, pp. 509-535, 1965.

[4] R. L. Kranz, W. J. Harris, and N. L. Carter, "Static fatigue of granite at $200^{\circ}$ C," Geophysical Research Letters, vol. 9, no. 1, pp. $1-4,1982$.

[5] R. D. Dwivedi, R. K. Goel, V. V. R. Prasad, and A. Sinha, "Thermo-mechanical properties of Indian and other granites," International Journal of Rock Mechanics and Mining Sciences, vol. 45, no. 3, pp. 303-315, 2008.

[6] J. P. Zuo, K. Man, H. Cao, G. X. Yang, and C. P. Hu, "Study on constitutive equation of rock rheological model with thermomechanical coupling effects," Chinese Journal of Rock Mechanics and Engineering, vol. 27, supplement 1, pp. 2610-2616, 2008.

[7] B. P. Xi, Y. S. Zhao, Z. J. Wan, J. C. Zhao, and Y. Wang, "Study of constitutive equation of granite rheological model with thermomechanical coupling effects," Chinese Journal of Rock Mechanics and Engineering, vol. 28, no. 5, pp. 956-967, 2009.

[8] L. Chen, C. P. Wang, J. F. Liu et al., "A damage-mechanismbased creep model considering temperature effect in granite," Mechanics Research Communications, vol. 56, pp. 76-82, 2014.

[9] R. C. Koeller, "Applications of fractional calculus to the theory of viscoelasticity," Journal of Applied Mechanics, vol. 51, no. 2, pp. 299-307, 1984.

[10] T. Blaszczyk, J. Leszczynski, and E. Szymanek, "Numerical solution of composite left and right fractional Caputo derivative models for granular heat flow," Mechanics Research Communications, vol. 48, pp. 42-45, 2013.

[11] W. Grzesikiewicz, A. Wakulicz, and A. Zbiciak, "Non-linear problems of fractional calculus in modeling of mechanical systems," International Journal of Mechanical Sciences, vol. 70, pp. 90-98, 2013. 
[12] M. Cajić and M. P. Lazarević, "Fractional order spring/springpot/actuator element in a multibody system: application of an expansion formula," Mechanics Research Communications, vol. 62, pp. 44-56, 2014.

[13] W. Sumelka, "Fractional viscoplasticity," Mechanics Research Communications, vol. 56, pp. 31-36, 2014.

[14] H. W. Zhou, C. P. Wang, Z. Q. Duan, M. Zhang, and J. F. Liu, "Time-based fractional derivative approach to creep constitutive model of salt rock," Science China Physics, Mechanics and Astronomy, vol. 42, no. 3, pp. 310-318, 2012 (Chinese).

[15] H. W. Zhou, C. P. Wang, L. Mishnaevsky Jr., Z. Q. Duan, and J. Y. Ding, "A fractional derivative approach to full creep regions in salt rock," Mechanics of Time-Dependent Materials, vol.17, no. 3, pp. 413-425, 2013.

[16] F. Zhang, Q. Sheng, Z. Q. Zhu, and Y. H. Zhang, "Study on post-peak mechanical behavior and strain-softening model of three gorges grantie," Chinese Journal of Rock Mechanics and Engineering, vol. 27, supplement 1, pp. 2651-2655, 2008.

[17] Q. S. Liu, X. C. Xu, T. Yamaguchi, and C. Akio, "Testing study on mechanical properties of the three gorges granite concerning temperature and time," Chinese Journal of Rock Mechanics and Engineering, vol. 20, no. 5, pp. 715-719, 2001.

[18] Y. G. Zhu, Q. S. Liu, Y. S. Kang, and K. D. Liu, "Study of creep damage constitutive relation of granite considering thermal effect," Chinese Journal of Rock Mechanics and Engineering, vol. 30, no. 9, pp. 1882-1888, 2011.

[19] J. Wang, R. Su, W. M. Chen et al., "Deep geological disposal of high-level radioactive wastes in China," Chinese Journal of Rock Mechanics and Engineering, vol. 25, no. 4, pp. 649-658, 2006.

[20] Y. M. Liu, J. Wang, L. G. Than, and M. F. Cai, "Basic physicmechanical properties and time-temperature effect of deep intact rock from beishan preselected area for high-level radioactive waste disposal," Chinese Journal of Rock Mechanics and Engineering, vol. 26, no. 10, pp. 2034-2042, 2007.

[21] Y. X. Jin, M. Z. Min, W. M. Chen, and H. G. Zhao, "Study on granite characteristics of xinchang section of candidate Beishan area, Gansu Province," Chinese Journal of Rock Mechanics and Engineering, vol. 26, supplement 2, pp. 3974-3981, 2007.

[22] K. Adolfsson, M. Enelund, and P. Olsson, "On the fractional order model of viscoelasticity," Mechanics of Time-Dependent Materials, vol. 9, no. 1, pp. 15-34, 2005.

[23] G. W. S. Blair, "The role of psychophysics in rheology," Journal of Colloid Science, vol. 2, no. 1, pp. 21-32, 1947. 


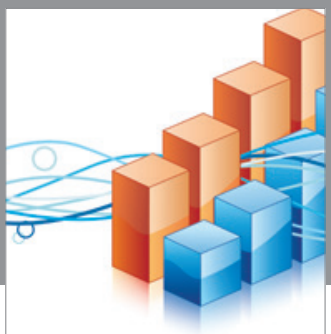

Advances in

Operations Research

vatem alat4

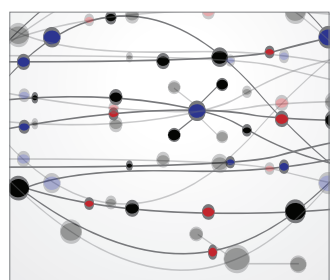

\section{The Scientific} World Journal
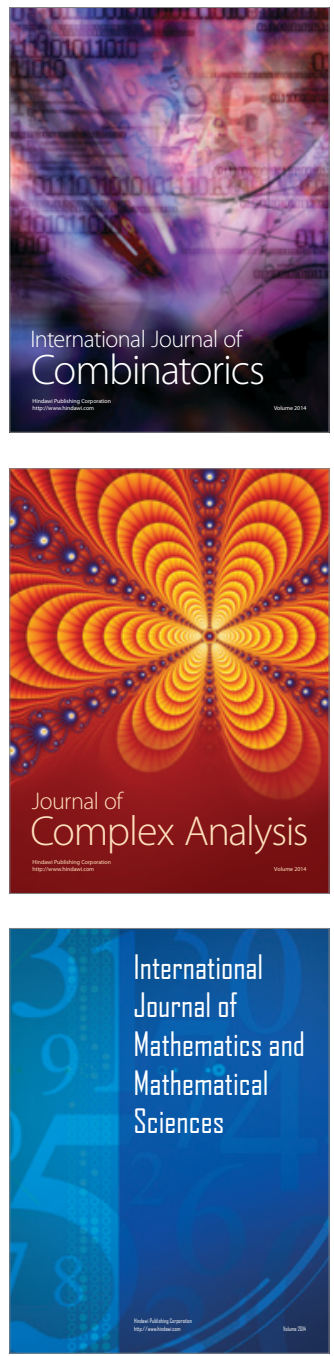
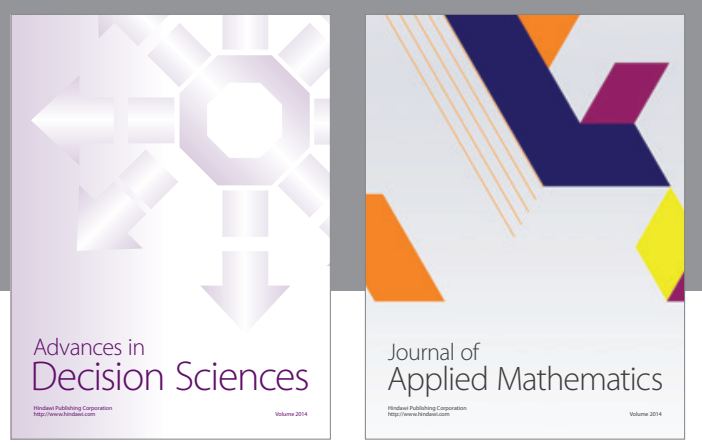

Algebra

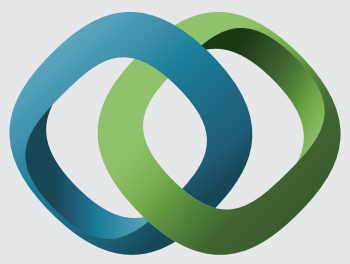

\section{Hindawi}

Submit your manuscripts at

http://www.hindawi.com
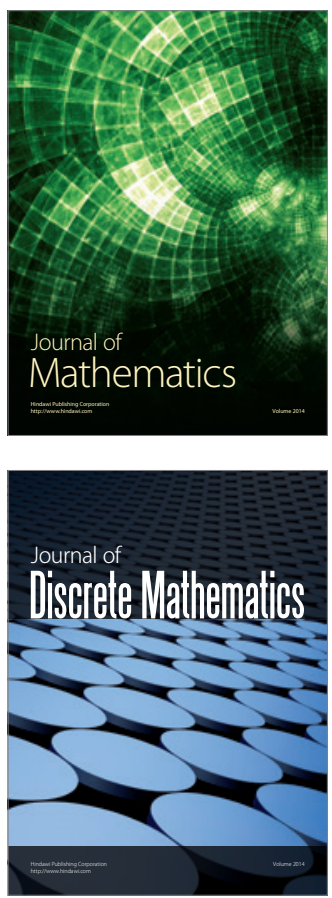

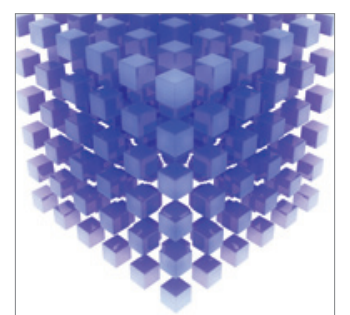

Mathematical Problems in Engineering
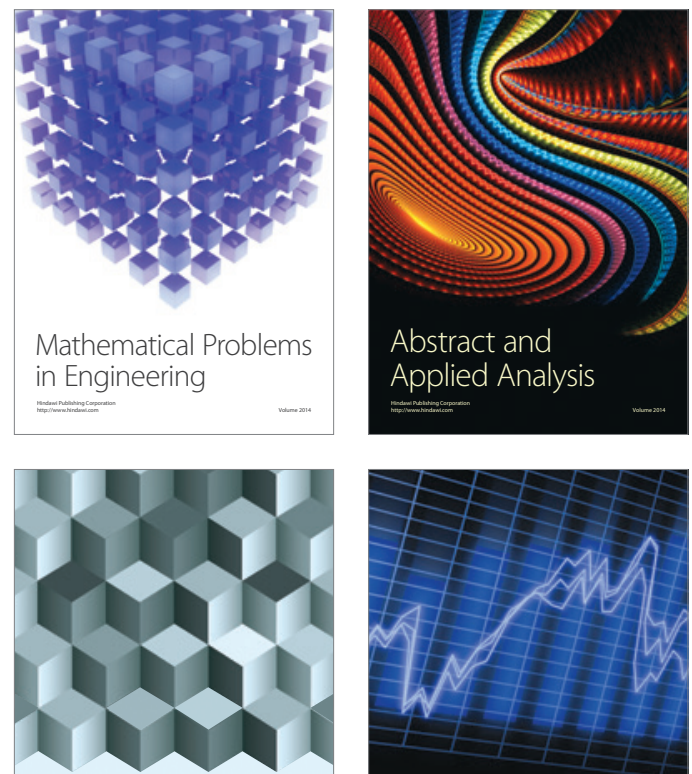

Journal of

Function Spaces

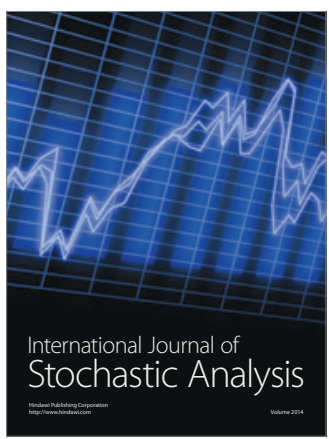

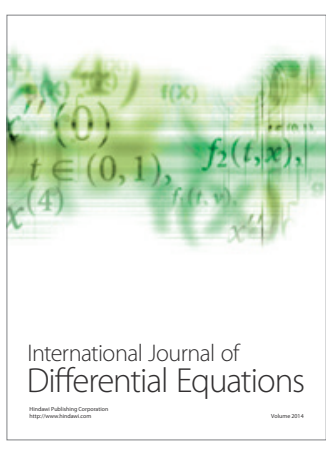
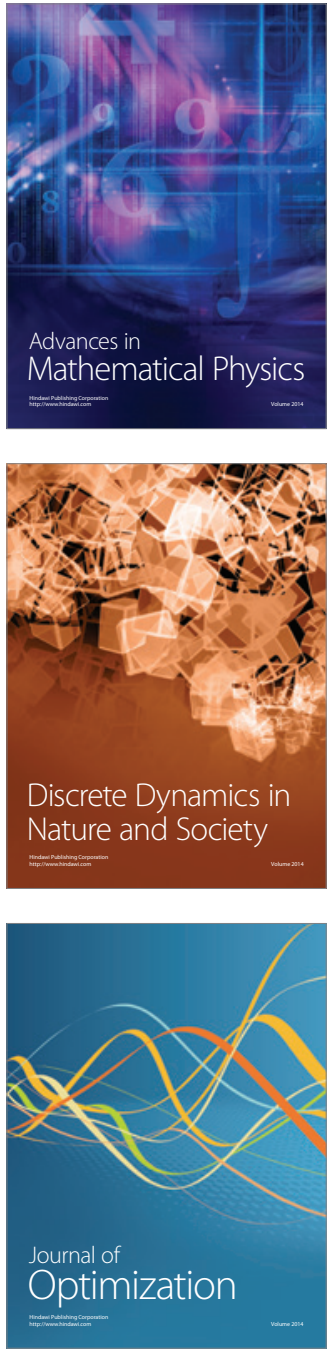